\title{
Habitantes leoneses se erigen en conservadores de la memoria de su territorio
}

Territorio Archivo es un proyecto propuesto por el creador audiovisual Chus Domínguez y desarrollado por la Fundación Cerezales Antonino y Cinia junto con "conservadores domésticos" y la colaboración de un grupo de investigación procedente de diversos ámbitos: estudios culturales, archivística, documentación, teoría de la imagen, visualización de datos y estructura de la información. El proyecto, iniciado en 2011, plantea, desde una lógica de no ficción, una lectura del territorio a partir de las fotografías que se encuentran en los domicilios de sus habitantes, fotografías que sirven como catalizadores de un diálogo sobre la comarca, que se cristaliza en un archivo vivo que permite ofrecer nuevas miradas al pasado y al presente.

Chus Domínguez | creador audiovisual

URL de la contribución <www.iaph.es/revistaph/index.php/revistaph/article/view/4122>

Una parte esencial del proyecto se desarrolla en los domicilios de los habitantes, donde estos seleccionan las fotografías que desean que pasen a formar parte del archivo, y donde se realizan grabaciones sonoras en las que los "conservadores domésticos" comentan cada fotografía, generándose así un relato vinculado a cada imagen. Para el desarrollo de esta etapa, el proyecto implica una intensa labor de mediación previa.

El archivo tiene una dimensión física, pues los documentos fotográficos permanecen en las viviendas de

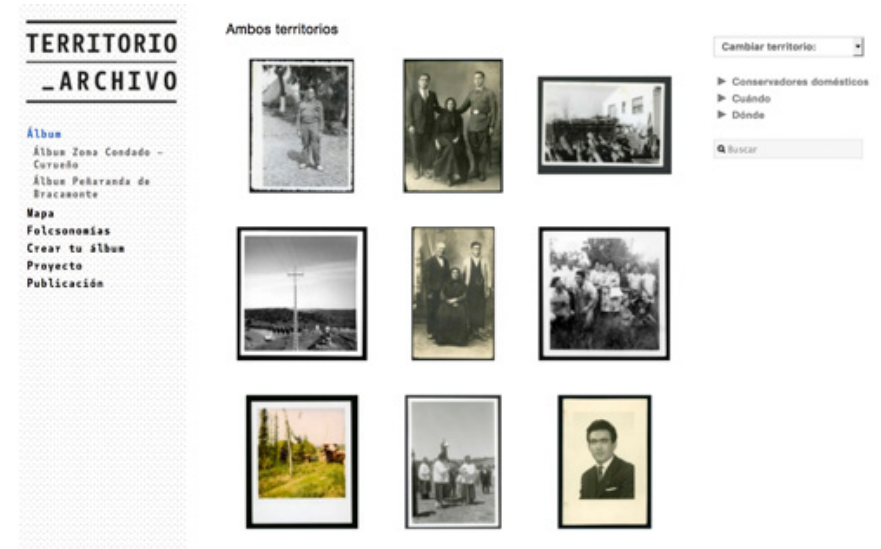

www.territorioarchivo.org

los habitantes, y una dimensión virtual en internet (www. territorioarchivo.org), donde se localizan las copias digitalizadas de las fotografías junto con las grabaciones sonoras e información asociada a cada documento fotográfico.

El acceso a los documentos en la página web simula el aspecto de los álbumes domésticos, al mostrar las fotografías en pequeño tamaño agrupadas en páginas. Al clicar en cada fotografía, esta se despliega en un tamaño mayor, acompañada por una ficha y un reproductor de sonido que permite escuchar el comentario sobre la misma. El menú principal de la página web ofrece otras opciones de acceso a los documentos: en función de su disposición geográfica en un mapa, según etiquetas denominadas folksonomías y según ciertos descriptores.

Una forma esencial que plantea el proyecto para acceder al fondo documental se basa en tener en cuenta la "voz del territorio". De todas las grabaciones sonoras recogidas y asociadas a cada imagen, se han extraído las palabras más representativas, y se han tomado como etiquetas (folksonomías) para caracterizar los documentos correspondientes. Este etiquetado social se despliega tanto como glosario, con posibilidad de acceso a cada uno de los términos seleccionados, como en forma de nube, que incluye las etiquetas más representadas, 


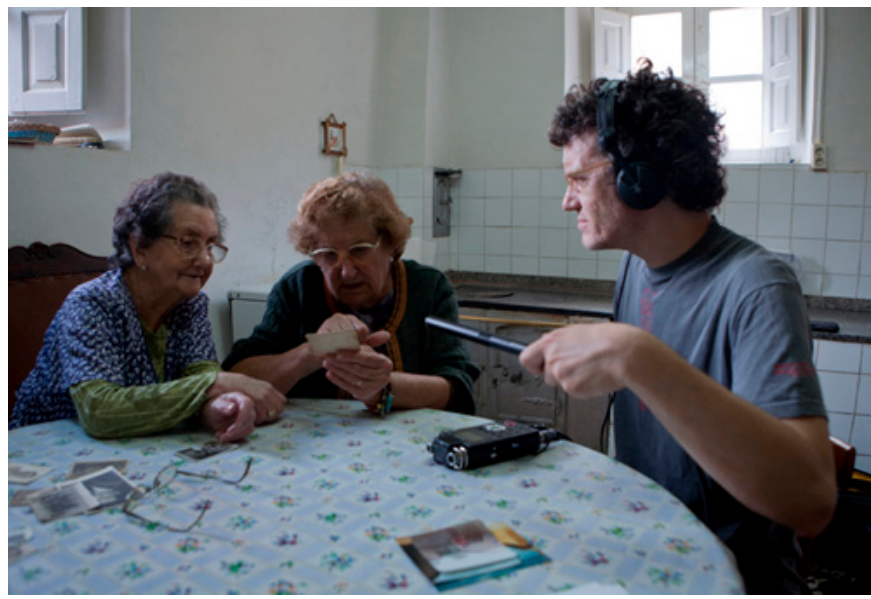

Grabación sonora durante el trabajo de campo | fotos Fundación Cerezales Antonino y Cinia

y que en sí misma constituye un mapa semántico del territorio.

Por otro lado, los descriptores que categorizan los documentos permiten acceder a los mismos de una forma estandarizada según las consideraciones académicas al uso sobre documentación fotográfica: autor, fecha de creación, tipo de documento, lugar, localidad, contexto social, tipo de actividad, etc. Se ha añadido además un grupo de descriptores denominados subjetivos, a través de los cuales se ha elegido categorizar los documentos en función de ciertos conceptos o términos que se han ido mostrando como esenciales en el desarrollo del proyecto y según el marco conceptual del mismo, como "presente/futuro", "comunidad", "solidaridad", "afectos", "religión", "sobre la fotografía", etc.

Junto con el desarrollo del archivo se ha planteado la necesidad de acompañarlo de un programa de activaciones, es decir, una serie de acciones que favorecen el contacto del archivo con la sociedad para que éste sea un elemento vivo, y para provocar un flujo bidireccional de información entre el archivo y el usuario. Entre las activaciones realizadas se ha llevado a cabo una exposición del archivo junto con abundante documentación de su proceso de generación, un taller con niños y niñas que han creado su propio "territorio archivo", intervenciones artísticas a partir del fondo documental, reuniones de los "conservadores domésticos" de las diferentes

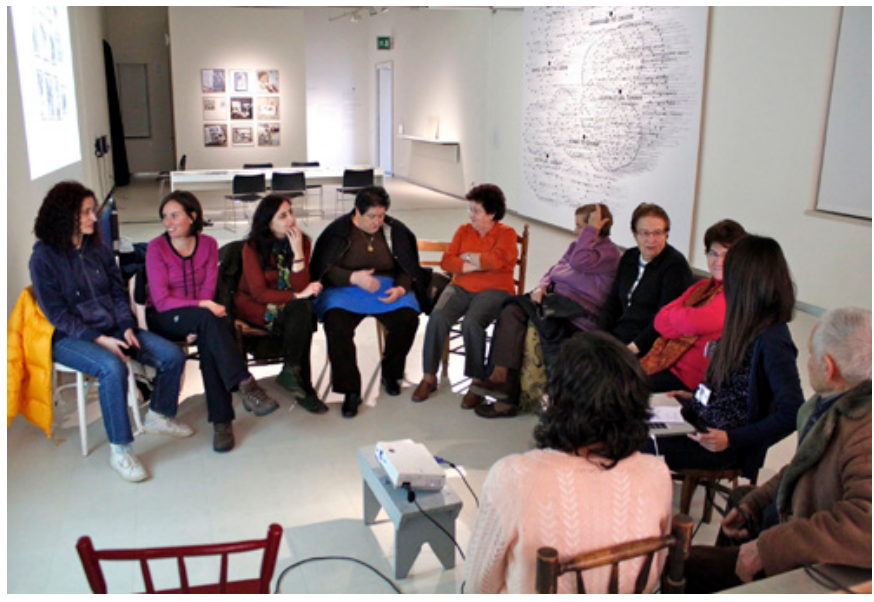

"Filandón" o reunión de activación del archivo

localidades, conferencias, etc. Se ha editado además una publicación que contiene todas las fotografías incluidas en la primera fase de desarrollo del archivo junto con textos de los expertos que han participado en el asesoramiento del proyecto (estos artículos se pueden consultar también en la página web).

Hasta el momento, el proyecto ha comprendido tres fases. Una primera que ha incluido seis pequeñas localidades en la comarca Condado-Curueño, en la provincia de León (Cerezales del Condado, Castro del Condado, Barrillos del Curueño, Devesa de Curueño, Barrio de Nuestra Señora y Ambasaguas de Curueño); una segunda que se centró en Peñaranda de Bracamonte, población principal de la comarca de Tierra de Peñaranda, en la provincia de Salamanca (esta segunda fase se realizó con la participación del Centro de Desarrollo Sociocultural de la Fundación Germán Sánchez Ruipérez); y una tercera que incorporó la localidad de Lugán, cercana al primer núcleo. El proyecto implica que se sigan incorporando nuevas localidades y documentos, a la vez que permite ser replicado en otros nodos territoriales.

Como su propio nombre indica, Territorio Archivo no solo plantea un acercamiento al territorio desde un archivo fotográfico, sino que además sugiere la posibilidad de entender el propio archivo como un territorio por explorar. 